\title{
Incorporation of iron oxide into CNT/GNF as a high performance supercapacitor electrode
}

\section{ABSTRCT}

$\mathrm{CNT} / \mathrm{GNF} / \mathrm{Fe}_{2} \mathrm{O}_{3}$ ternary composites were synthesized via a simple hydrothermal route. The electrochemical findings reveal that the incorporation of iron oxide $\left(\mathrm{Fe}_{2} \mathrm{O}_{3}\right)$ into CNT/GNF $\left(174 \mathrm{~F} \mathrm{~g}^{-1}\right)$ boosts the specific capacitance (Cs) to $307 \mathrm{Fg}^{-1}$ at $10 \mathrm{mV} \mathrm{s}^{-1}$. The system also shows good capacity retention, as it maintained $92 \%$ of its original capacitance after 200 cyclic voltammetry cycles. Physicochemical characterization shows that $\mathrm{Fe}_{2} \mathrm{O}_{3}$ was anchored randomly on the CNT/GNF sidewalls, forming a network for facile ion diffusion. The improved supercapacitance of $\mathrm{CNT} / \mathrm{GNF} / \mathrm{Fe}_{2} \mathrm{O}_{3}$ can be ascribed to the synergistic effect of the double-layer capacitance of CNT/GNF and the pseudocapacitance of $\mathrm{Fe}_{2} \mathrm{O}_{3}$.

Keyword: CNT; GNF; Iron oxide; Supercapacitors; Physicochemical; Electrochemical. 